\title{
INTERFACES DA NATUREZA E DA SOCIEDADE NA OBRA DE GABRIEL TARDE $^{1}$
}

Rafael Henrique Teixeira (UFSCar) ${ }^{2}$

rafael.discord@gmail.com

Resumo: $\mathrm{O}$ presente artigo trata da monadologia e da filosofia da imitação de Gabriel Tarde do ponto de vista de sua complementaridade na constituição de um "ponto de vista sociológico universal", interpretação sociológica de todos os fenômenos, materiais (vibratórios), biológicos (hereditários) e humanos (imitativos). De um lado Tarde estabelece uma neo-monadologia ao romper com Leibniz liberando as mônadas da clausura em que este as condenava. Abertas, as mônadas passam a se associar via possessão recíproca, constituindo assim os acordos e harmonias que Leibniz explicava pelo sistema da harmonia preestabelecida. Esses acordos monádicos são sociedades de uma miríade de tipos, eles explicam a constituição de todo e qualquer fenômeno. De outro lado Tarde se esforça, por meio da sua filosofia da imitação, em fornecer um substrato científico à sociologia então nascente, tomando a imitação como o elemento antropológico de uma atividade associativa que se manifesta na totalidade do cosmos. Depurando assim o objeto próprio de uma ciência do social, Tarde acaba por descobrir um regime de causalidade que, pela clareza pela qual se oferece ao observador, é estendida à totalidade da natureza, iluminando o fundo obscuro e inacessível à observação direta no qual se efetuam as associações monádicas.

Palavras-chave: mônada; acordo; ciência; sociedade.

\section{Segundo Bergson (1909a, p. 379), o essencial da filosofia de Gabriel Tarde é um ponto de vista original sobre a cau-}

\footnotetext{
${ }^{1}$ Recebido em: 05-01-2015/ Aprovado em: 22-07-2015/Publicado on-line: 31-08-2015.

${ }^{2}$ Rafael Henrique Teixeira é recém doutor pela Universidade Federal de São Carlos, São Carlos, SP, Brasil.
} 
salidade observada nas sociedades humanas, nas quais "um indivíduo inventa e outros o imitam". Na filosofia da imitação tardiana, deduzida de "visões metafísicas profundas sobre a natureza do universo, dos elementos que o compõem, e das ações que esses elementos exercem uns sobre os outros", Bergson (1909b, p. 376) vê uma das manifestações mais originais do cenário intelectual do qual participava com Tarde ${ }^{3}$. Meu objetivo é elucidar essa ligação que Bergson entrevê entre as "visões metafísicas" de Tarde e a "ciência do social" que busca instituir a luz de sua filosofia da imitação. Algo que se afirma no próprio título de um de seus mais célebres ensaios, Monadologie et sociologie (1893). É a natureza dessa conjunção "e" que buscarei elucidar, em outros termos: como um sistema monadológico pode se prolongar em ciência do social nas mãos de Tarde e como essa ciência do social acaba por informar aspectos essenciais do dinamismo que anima a natureza. Ao fim retiraremos algumas consequências dessas operações.

O recurso às mônadas nada tem de artificial, defende nosso autor. Afinal, a ciência caminharia nessa direção desde a pulverização da individualidade dos corpos celestes operada por Newton, tendência que conduz, aos olhos de Tarde, às resoluções do espiritualismo leibziniano, ao reconhecimento de uma atividade em todos os planos da natureza que é da alçada do espírito. A cada unidade ou agregado material, célula, molécula, átomo "é inerente um princípio animado, um eu mais ou menos rudimentar" 4

\footnotetext{
${ }^{3}$ Quanto ao reconhecimento dessa originalidade por parte de Bergson, encontramos sua expressão em Les deux sources de la morale et de la religion (1932), quando Bergson apela ao contágio do exemplo para descrever a ação do místico na abertura das sociedades que a vida depositou ao longo de uma de suas linhas de evolução.

${ }^{4}$ Tarde (1893, p. 33-37) identifica essa inclinação na química de Wurtz, nas doutrinas da evoluCont.
} 


\section{(TARDE 1876, p. 65) .}

As mônadas, filhas de Leibniz, realizaram um longo caminho desde seu pai. Por diversas vias independentes elas se insinuam, a revelia dos próprios cientistas, no coração da ciência contemporânea. É assinalável que todas as hipóteses secundárias implicadas nessa grande hipótese naquilo que ela tem de essencial, senão de leibziniana, estão em vias de ser estabelecidas cientificamente. Ela implica, com efeito, primeiramente a redução a uma única dessas duas entidades, a matéria e o espírito, confundidas na segunda, e ao mesmo tempo a multiplicação prodigiosa dos agentes espirituais do mundo. Ela supõe, em outros termos, a descontinuidade dos elementos e a homogeneidade de seu ser. Aliás, é somente com essa dupla condição que o universo é translucido até seu fundo aos olhos da inteligência (TARDE 1893, p. 33).

O infinitesimal leibziniano possui um alcance ontológico e cosmológico (MILET 1974, p. 67) que, de meu ponto de vista, Tarde parece ter reconhecido ao afirmar que "a fonte e a razão do finito está no infinitamente pequeno" (TARDE 1893, p. 37). Há almas ou mônadas por toda parte e a natureza é plena de diferenças. Leibniz (1714a, p. 109) afirmara que se cada "porção da matéria pode ser concebida como um jardim cheio de plantas e como um lago cheio de peixes", igualmente "cada ramo da planta, cada membro do Animal, cada gota de suas disposições é ainda semelhante jardim ou semelhante lago". Tarde está de acordo com Leibniz a esse respeito. Mais que de acordo na

ção de Perrier e Cournot, na hipótese dos átomos-turbilhões de Thompson, na teoria celular de Schwann, etc. Exemplifiquemos esse recurso tardiano às ciências naturais com sua apropriação das conclusões de Haeckel. Este, afirma Tarde (1876, p. 53), "o mais fervente e um dos mais sábios discípulos de Darwin, dá a doutrina da evolução uma interpretação monadológica, leibziniana, das mais assinaláveis. Não poderíamos espiritualizar a matéria de modo mais completo. "A alma do átomo", diz Haeckel com razão". De modo geral, o que Tarde visa com a defesa de um espiritualismo identificado a Leibniz que teria nos desenvolvimentos da ciência como que sua confirmação tardia não é propriamente - ou, ao menos, não diretamente - o dualismo cartesiano, mas aquela que seria uma consequência natural de uma visão unitária das mudanças ocorridas no universo, o evolucionismo de Spencer. 
verdade: esse é de seu ponto de vista o único modo de a natureza se tornar translúcida, "até seu fundo", aos olhos da inteligência .

Podemos afirmar que Tarde encontra em Leibniz, na multiplicação das substâncias que ele opera, espécie de antídoto às tentativas da ciência e da filosofia em "Estreitar profundamente esse grande Universo e torná-lo pequeno ao ponto de fazer com que entre em uma fórmula, e desse modo em um cérebro árido e seco" (TARDE 1876, p. 64). Mas, a inspiração leibziniana que anima a filosofia da natureza de Tarde não pode dissimular seu intento reformador. Caso contrário, sua monadologia não seria acompanhada do qualificativo "renovada", não se intitularia uma "neomonadologia". Tarde opera uma abertura das mônadas, caracterizando sua atividade como produtiva e não meramente como um desdobramento de caráter expressivo como faz Leibniz. Como consequência, Tarde terá de tratar das composições harmônicas da natureza sem o recurso ao acomodamento ideal entre as substâncias, ou seja, sem o sistema da harmonia preestabelecida - que será como que substituído pelo modelo da causalidade exemplar .

Antes de tratarmos diretamente da filosofia da natureza de Tarde é preciso apontar algumas teses essenciais de Leibniz. Sob o risco de simplificação, esse apontamento será excessivamente esquemático. Nosso objetivo é apenas ilustrar os pontos nos quais a filosofia de Leibniz será objeto de exame crítico e de reformulação por parte de Tarde - sem deixar de reconhecer, claro, algo que podemos reconhecer como uma inspiração leibziniana, como um ponto de partida aberto a desenvolvimentos insuspeitados. 


\section{ALGUNS ASPECTOS DA MONADOLOGIA DE LEIBNIZ.}

Variação e mudança, elementos constitutivos das mônadas, "vêm de um princípio interno, pois uma causa externa não poderia influir em seu interior" (LEIBNIZ 1714a, p. 96). Cada uma envolve o universo inteiro em suas percepções e a sequência dessas percepções é regulada por sua natureza particular. Suas ações são as percepções que lhe são interiores e suas variações. $\mathrm{O}$ estado passageiro que envolve uma multidão na unidade é o que Leibniz chama de percepção, a ação do princípio interno que realiza a passagem de uma percepção a outra é chamada apetição. Cada mônada conhece tudo confusamente, somente Deus possui um conhecimento distinto de tudo. Uma mônada será tão mais perfeita quanto mais possuir percepções distintas e, desse modo, aproximar-se de Deus.

Individualmente, cada mônada possui uma zona clara de expressão que lhe pertence exclusivamente. Esta diz respeito ao seu corpo. As mônadas "não possuem janelas pelas quais alguma coisa possa entrar ou sair" (LEIBNIZ 1714a, p. 96). Mas elas expressam um mesmo universo, logo, "por mais que sejam fechadas, as mônadas não são monacais, não são celas de monges, pois incluem o mesmo mundo, solidárias e não solitárias" (DELEUZE 1988, p. 227). Cada substância simples ou mônada possui relações que exprimem todas as outras, que exprimem, assim, o universo do qual fazem parte. Cada uma "é como um mundo inteiro e como um espelho de Deus ou então de todo o universo, que ela exprime cada uma a seu modo, quase como uma mesma cidade é diversamente representada segundo as diferentes situações daquele que a observa" (LEIBNIZ 1686, p. 44). Mas, ainda que cada mônada represente "todo" o uni- 
verso ao incluí-lo em suas percepções internas, ela representa "mais distintamente" aquilo que afeta o corpo do qual ela é a enteléquia ou alma, corpo este que se encontra conectado com toda a matéria que constitui o mundo expressamente contido em cada mônada .

(...) como tudo está ligado devido à plenitude do mundo, e cada corpo atua em maior ou menor medida sobre cada um dos demais, segundo a distância, sendo por sua vez afetado por reação, segue-se que cada Mônada é um espelho vivo, ou dotado de ação interna, representativo do universo, segundo seu ponto de vista, e tão regulado como o próprio universo (LEIBNIZ 1714b, p. 154).

Porém, dizer que uma mônada possui um corpo não implica reconhecer uma influência física de uma substância sobre outra, do corpo sobre alma ou vice-versa. Reconhecer um acordo entre alma e corpo é coisa distinta de admitir a possibilidade de uma mútua modificação ou influência. Leibniz (1714a, p. 95) é taxativo ao afirmar que não há meio de explicar "como uma Mônada possa ser alterada ou modificada em seu interior por alguma outra criatura". Existe uma conformidade natural entre alma e corpo em virtude de uma harmonia preestabelecida. As almas agem segundo as leis das causas finais por apetições, os corpos segundo as leis das causas eficientes ou dos movimentos e os dois reinos são harmônicos sem que possuam influência recíproca. "A alma segue suas próprias leis, e os corpos também as suas, e eles se encontram em virtude da harmonia preestabelecida entre todas as substâncias, pois elas são todas representações de um mesmo Universo” (LEIBNIZ 1714a, p. 111). Essa conformidade, Leibniz observa, não se restringe às relações de uma mônada com seu corpo, mas se faz presente entre a totalidade das substâncias simples .

Tão perfeito acordo entre substâncias que não possuem 
comunicação direta apenas pode vir de uma causa comum, que fornece a cada uma a força interna que produz tudo o que lhe acontecerá sem o recurso a nenhuma criatura que lhe seja exterior. Há apenas uma maneira de explicar esse acordo, dirá Leibniz (1695, p. 85), "a via da harmonia preestabelecida" artificio divino que formou desde o início cada uma das substâncias de "maneira tão perfeita e regulada com tanta exatidão que, apenas seguindo suas próprias leis, que receberam com seu ser", elas acabam por entrar em perfeito acordo com as demais substâncias. Tudo está regulado de antemão com tanta ordem e correspondência quanto possível. A solidariedade de todos os seres faz da harmonia universal, da qual a correspondência da alma com o corpo é um caso, algo de completamente distinto de um acordo resultante de atividades individuais independentes. Como afirma Fichant (1998, p. 133), o concerto é originariamente orquestrado. Leibniz (1710, p. 329) pode então afirmar que uma das regras de seu sistema da harmonia geral é "que o presente é prenhe de futuro", de modo que aquele que vê tudo, Deus, "vê em cada parte do universo o universo inteiro" em razão da perfeita conexão das coisas .

Esse é um ponto que nos permite, por contraste, passar ao exame da monadologia de Tarde. O presente é prenhe de futuro: essa afirmação é igualmente verdadeira para Tarde. Porém, não em virtude de um expresso comum no qual leríamos, com os olhos de Deus, a perfeita conexão entre todas as substâncias, mas em virtude de um elã proteiforme e anárquico, como reconhece Milet (2006, p. 142), composto pela somatória dos elementos adormecidos em cada figuração estática da natureza, cada elemento carregando o projeto, a ideia das conexões de amanhã. O presente é prenhe de futuros condicionais: a realização de um ou outro 
dentre eles, modulação ou acordo temporário, é uma interação seguida de uma seleção, não o desdobramento de leis internas que expressam a perfeita conexão das coisas sem que uma haja sobre outra. Veremos que cada acordo é como que uma solução de continuidade estabelecida entre a heterogeneidade dos elementos da natureza e que ele implica uma entre-penetração entre as substâncias. Algo distinto do que quer Leibniz (1686, p. 78), para quem toda substância tem uma perfeita espontaneidade na medida em "que tudo o que lhe acontece é uma sequência de sua ideia ou de seu ser, e que nada a determina do exterior exceto Deus”.

\section{A INSTITUIÇÃO DE UMA NOVA ATIVIDADE RELACIONAL NO CAMPO DA NATUREZA.}

Vimos que aos olhos de Tarde a ciência caminhava na direção do espiritualismo leibziniano ao multiplicar os agentes da natureza e unificar a dualidade cartesiana. Se isso resulta em um "psicomorfismo inevitável”, afirma Tarde, resta admitir, com os monadologistas, "que todo o universo exterior é composto de almas outras que a minha, mas no fundo semelhantes à minha" (TARDE 1893, p. 44), caracterizadas por um "misterioso interior" (TARDE 1876, p. 63) inacessível ao mecanicismo.

Leibniz, ao conceber suas mônadas, não obedecia a uma tendência unitária; se ele lutou contra a teoria das duas substâncias, uma extensa, a outra pensante, imposta por Descartes, não é que ele tenha achado demasiado duas; ao contrário, ele as multiplicou ao infinito; tantas mônadas, tantas substâncias diferentes. Note bem, diferentes; esse grande espírito evitou dar a esse belo Universo rico e variado elementos semelhantes, calcados uns sobre os outros identicamente, como os átomos hipotéticos de nossos químicos; suas mônadas eram distintas, caracterizadas individualmente, como nós somos entre nós, como todas as coisas são entre elas; e ele mostrou assim a importân- 
cia que é preciso conceder à diversidade dos fenômenos, ou seja, à sua essência e beleza (TARDE 1876, p. 66).

Mas rapidamente observamos Tarde trilhar os primeiros passos que o levarão a distanciar-se de seu mestre. $\mathrm{O}$ que fornece o testemunho de propriedades "interiores" 5 às mônadas são suas "manifestações exteriores" (TARDE 1876, p. 67). Ora, não podemos entrever aí um deslocamento essencial? Não observamos em Leibniz um primado da interioridade expressiva das mônadas, que incluem o universo em suas percepções mais ou menos confusas pelo simples desdobramento de suas leis internas? Vejamos para onde Tarde nos conduzirá: suas mônadas, como as de Leibniz, são caracterizadas por sua atividade - não mais expressiva, mas possessiva - e por uma espécie de dualidade interna - não mais entre apetites e percepções, mas entre crenças e desejos .

Todos os fenômenos se explicam por fatores psicológicos: crenças e desejos presentes em toda a escala dos seres. A atividade espiritual se define pela crença, pelo desejo e por seu ponto de aplicação, o sentir. Os dois primeiros termos são relativamente independentes das sensações. $\mathrm{O}$ sentir é livre, de direito, de toda ação da crença e do desejo, ainda que seja o seu ponto de aplicação. Distintas mas indissociáveis das forças psicológicas, as sensações são o seu suporte. Crenças e desejos nelas penetram sem constituí-las, fazem-nas variar e estabelecem entre elas relações sem, contudo, confundi-las (TARDE 1880, p. 251).

\footnotetext{
${ }^{5} \mathrm{O}$ termo "propriedade interior" deve ser interpretado de duas maneiras: (1) propriedades que caracterizam uma existência espiritual qualquer (2) e propriedade no sentido da possessão recíproca de uma mônada por outra. De um lado crenças e desejos, propriedades da alma, de outro a ação monádica, que é uma ação possessiva. Trata-se, pelo momento, do primeiro sentido do termo.
} 
As sensações são heterogêneas, ao passo que a crença, energia de contração mental, permanece a mesma por sob suas variações - do mesmo modo que o desejo que, malgrado a diversidade de seus objetos, varia em termos de graus de intensidade (TARDE 1876, p. 111). Crenças e desejos são a bifurcação psicológica e o eixo da reação do eu não apenas às sensações, mas também às crenças e desejos de "outros" seres espirituais. Essa dualidade psicológica nada tem de antropomórfica. Trata-se de um gênero de atividade que é o índice de uma atitude do espírito em todas as escalas da natureza (MONTEBELLO 2003, p. 124). Encontramos nos animais, por exemplo, sensações que nos são desconhecidas. Quando o cão fareja não temos ideia da notação sensitiva que lhe permite diferenciar o odor. Mas, quando ele segue uma lebre, ele "crê" se aproximar dela e “deseja” alcançá-la (TARDE 1895a, p. 87).

Tarde assinala uma dupla reação às impressões do exterior: um exterior sensitivo, das impressões produzidas no espírito pelas sensações qualitativas objeto do exercício da atividade psicológica e um exterior relacional, das intensidades psicológicas transmissíveis e presentes em outros seres. Dupla maneira pela qual o espírito se apresenta como modificável. Essa constatação é fundamental para a compreensão das subversões que Tarde operará na inspiração leibziniana que anima sua monadologia. Afinal, suas mônadas serão caracterizadas por uma atividade distinta do simples desdobramento de suas leis internas. As mudanças, verdadeiras conversões, serão fruto de uma influência de outras criaturas, relação de caráter horizontal que contrasta com a verticalidade do acomodamento ideal das substâncias leibzinianas. Nascidas independentes, refratárias aos desígnios de um ideal primitivo, os acordos são, como veremos, 
uma colaboração inter-monádica .

Temos de nos perguntar, afirma Tarde, como explicar o acordo entre mônadas que nascem separadas, independentes e ávidas. Isso a monadologia de Leibniz, que faz de cada mônada uma câmara obscura em que as demais se inscrevem sob um ângulo especial, deixa por explicar - ao menos do ponto de vista da nova monadologia de Tarde, que pretende se livrar da hipótese da harmonia preestabelecida. E uma vez mais Tarde recorre à ciência. A mesma ciência que trilhava os caminhos do espiritualismo de Leibniz convida, agora, a concepção de mônadas abertas que se interpenetram, a uma monadologia renovada. Para Tarde, a descoberta newtoniana da atração e da ação a distância dos elementos materiais uns sobre os outros coloca em cheque a suposta impenetrabilidade da matéria, permitindo que cada átomo seja tomado como uma esfera de ação infinitamente ampliada. $\mathrm{O}$ átomo se torna um meio universal ou que aspira a sê-lo, "não somente, como queria Leibniz, um microcosmo, mas o cosmos inteiro conquistado e absorvido por um único ser" (TARDE 1893, p. 87) .

Enquanto as mônadas leibzinianas "expressam" o mundo no qual Deus tudo fez de modo a preestabelecer toda ordem e artifício futuro, as de Tarde "constroem" o mundo sem plano prévio. Cada mônada possui uma avidez característica, uma ambição as move. Sua diversidade se deve ao fato de serem totalidades especiais. Cada uma não é apenas uma unidade, mas também uma virtualidade de determinado gênero, que encarna uma ideia cósmica .

(...) se há um fato que deveria ter impressionado todos os olhos é a avidez, a ambição imensa que de um lado a outro do mundo, do átomo vibrante ou do pequeno animal prolífico, ao rei conquistador, preenche e move os seres. Toda possibilidade tende a se realizar, 
toda realidade tende a se universalizar (...) daí esse transbordamento de variações por cima e através de todos os temas vivos, físicos e sociais (TARDE 1893, p. 95).

Essa voracidade de cada mônada, esse intento de afirmação de sua substância própria, acaba por se ligar a outra característica não menos fundamental, a qual acaba por ser uma espécie de freio, de moderador natural dessa fonte infinita de variação. Entregues a si mesmas as mônadas nada podem. Elas têm de se reunir, o que fazem via possessão recíproca (TARDE 1893, p. 66). Do mesmo modo que os elementos são agentes, eles são proprietários. Sua ação revela-se como uma mudança produzida na natureza de sua possessão. A verdadeira propriedade de um proprietário é sempre um conjunto de outros proprietários, ou seja, outras mônadas .

Cada uma delas absorve o mundo a si, o que significa apreender-se melhor a si mesma. Elas realmente fazem parte umas das outras, mas elas podem se pertencer mais ou menos, e cada uma delas aspira ao mais alto grau de possessão; daí sua concentração gradual; em outros termos, elas podem se pertencer de mil maneiras diferentes, e cada uma delas aspira conhecer novas maneiras de se apropriar de suas semelhantes. Daí suas transformações (TARDE 1893, p. 93).

A possessão é um fato universal, aquilo que melhor exprime a formação de um fenômeno qualquer. Todo ser quer não se deixar apropriar aos seres exteriores, mas apropriá-los. Tarde sugere assim uma atividade de apropriação distinta de uma noção antropomórfica de propriedade. Não se trata de um proprietário que se apropria de uma "coisa" de natureza outra da do proprietário. As apropriações são interpenetrações de existências espirituais que se modulam reciprocamente, que convergem temporariamente para um mesmo fim. São as almas que possuem e que são possuídas, 
que formam as dinâmicas de possessão ou pontos de intersecção em que se dão as conexões entre crenças e desejos: atividade possessiva que é, ao mesmo tempo, associativa, e que dá ensejo a concentrações graduais entre elementos heterogêneos. A possessão é uma espécie de propaganda, comunicação de elemento a elemento do desígnio pertencente a um elemento iniciador que promove a conversão, a transformação interna de elementos outros nos quais ele faz entrar seu desígnio próprio para ser por eles repetido. De modo que o plano cósmico de cada mônada tende a se realizar mais ou menos pela sua maior ou menor potência de imprimir crenças e desejos em outras mônadas

$\mathrm{Na}$ ausência do Deus leibziniano, que instituía a correspondência entre as mônadas, as regularidades se explicam pela afirmação temporária de mônadas que impõem seu desígnio sobre outras mônadas. No universo leibziniano a harmonia preestabelecida coloca uma relação universal que interdita toda relação intramundana de interdependência e interação por conexões horizontais entre as mônadas. Tarde, por sua vez, investe as mônadas de uma atividade produtiva que as libera da harmonia que impedia toda ação real e influência física e que reservava a Deus a razão plena da compossibilidade das coisas (ALLIEZ 1999, p. 20) .

Todos os acordos, tipos e similitudes da natureza são pontos de intersecção, diferenças convergentes, "focos nos quais banalidades combinadas formam um ser original, nos quais qualidades, separadamente susceptíveis de graus e medidas, compõem uma realidade sui generis, radiante de novidades imprevistas e maravilhosas" (TARDE 1895b, p. 420). Toda similitude é o resultado de uma assimilação 
produzida por uma repetição daquilo que foi, no início, uma imposição individual. É verdade que não há condições de todas as virtualidades, de todos os universos em projeto carregados por cada mônada se realizarem. Para cada desenvolvimento milhões de abortos são necessários (TARDE 1893, p. 96). A afirmação de uma diferença é um ato de seleção e de constituição que edifica uma nova cooperação entre forças, ela exprime uma seleção da multiplicidade de relações entre as forças que, em meio à infinitude de suas combinações, atualiza apenas uma (LAZZARATO 2002, p. 381-382). O real é apenas um dispêndio do possível, que não é outra coisa senão o conjunto de possíveis não realizados ou das certezas condicionais ${ }^{6}$ (TARDE 1874, p. 14) .

Em um "sistema monadológico todo fenômeno é uma nebulosa resolúvel em ações emanadas de uma multidão de agentes", postula Tarde (1893, p. 55), "pequenos deuses invisíveis e inumeráveis". Esse politeísmo, "esse miriateísmo, deixa por explicar o acordo universal dos fenômenos, por imperfeito que ele seja" (TARDE 1893, p. 55). Ora, sabemos que essa acusação é dirigida a Leibniz. Mas sabemos igualmente que seu sistema da harmonia preestabelecida vem explicar, precisamente, o acordo não apenas entre alma

\footnotetext{
${ }^{6}$ Para Tarde (1874, p. 28) o universo tal qual conhecemos "deve sua existência à imolação de milhões de outros universos", dentre os quais encontraríamos talvez, malgrado a suposição de Leibniz, "melhores e mais belos do que este". O mundo dos possíveis é constituído pelas potencialidades temporariamente adormecidas sob o jugo de uma mônada dominante, temporariamente desempenhando o ritmo que lhes é imposto. É a infinitude que subsiste em estado de latência naquilo que ajuda temporariamente a constituir: no fundo de cada coisa "há toda coisa real ou possível" (TARDE 1893, p. 58). Por detrás da constituição fenomênica da natureza há a reunião de todas as lutas de influência entre os elementos que buscam impor seu projeto de universo. O embotamento dos possíveis forma uma série que vai dos possíveis ao atual. Como é preciso um conjunto de condições para que algo passe a existência, cada condição aproxima em um grau o possível da existência, o impossível do possível, o virtual do atual (MONTEBELLO 2003, p. 135). Cada vez que uma realidade "é sufocada ou impedida de nascer, ela enterra com ela seu cotejo de possíveis; mas também, a cada vez que uma realidade nasce ela faz avançar em um grau seu cotejo de possíveis" (TARDE 1895a, p. 259).
} 
e corpo, mas entre todas as substâncias simples. De modo que temos de nos perguntar o que essa acusação, indispensável à constituição da nova monadologia, quer dizer e, sobretudo, que campo se abre à investigação tardiana sua dupla atitude: a espiritualização e multiplicação das agências da natureza associada à recusa do sistema da harmonia preestabelecida .

O que o universo descrito por Tarde apresenta é uma harmonização progressiva a partir e por meio de diferenças originariamente livres e indiferentes a um plano preexistente. Os acordos existem e apontam para uma tendência que não é menos importante que a variação. Não basta saber "em qual sentido é preciso entender o grande e belo princípio da diferenciação", mas também como "conciliá-lo como convém com o princípio da coordenação universal" (TARDE 1893, p. 71). Podemos inclusive admitir que existam "fins" na natureza, confessa Tarde. Porém, não em termos do finalismo de Leibniz, mas "fins" de inumeráveis agentes elementares (TARDE 1895a, p. 228). A partir da concatenação desses fins isentos de finalidade Tarde identifica na natureza uma potência de harmonia. Toda regularidade, na qualidade de repetição de um ritmo que é o desígnio que uma mônada impôs às demais, é uma harmonização. O problema dos adeptos das causas finais não é, nesses termos, o uso abusivo da noção de finalidade, mas, ao contrário, um uso muito restrito, limitado a uma unidade pouco verídica.

Não há um fim na natureza, um fim com relação ao qual todo o resto é meio; há uma multidão infinita de fins que buscam se utilizar uns aos outros. Cada organismo, e em cada organismo cada célula, e mesmo talvez em cada célula, cada elemento celular, tem sua pequena providencia própria (...) somos conduzidos a pensar que a força harmonizante (...) não é imensa e única, exterior e superior, mas in- 
finitamente multiplicada, infinitesimal e interna (TARDE 1898, p. 112) .

De uma entre-possessão recíproca surgem os acordos e repetições que configuram as regularidades observáveis na natureza. Dessa negociação continuada entre pequenas diferenças, mobilidade universal de pequenas finalidades acordadas temporariamente, Tarde deduz uma "potência de harmonia". À finalidade geral, aquela da harmonia "preestabelecida", se opõe uma doutrina da evolução tomada como harmonia "co-estabelecida" (TARDE 1901a, p. 123). Ou seja, as harmonias existem e sua razão de ser não reside na idealidade de uma composição do entendimento divino, mas na atividade relacional continuada dos agentes da natureza .

Alguns destes, imprimindo suas marcas de crenças e desejos nas outras mônadas, fazendo-as variar, magnetizandoas segundo seus desígnios, segundo seu projeto de universo, constituem estabilidades relativas que conduzem temporariamente a mobilidade universal dos agentes monádicos a adquirir a forma estática - e de direito provisória - sobre a qual o homem atual exerce sua atividade e que se faz objeto da ciência e da especulação do filósofo. As três principais formas da Repetição universal, a ondulação, a geração, e a imitação são, portanto, como procedimentos de governo e instrumentos de conquista, associações ou acordos temporários que dão lugar a três tipos de invasão, "física, vital, social: a irradiação vibratória, a expansão geradora, o contágio do exemplo" (TARDE 1893, p. 96) - como que formas visíveis do jogo de forças invisível que sustenta essa aparente e superficial regularidade da natureza .

Pudemos observar que as mônadas não podem afirmar sua substância própria sem o recurso a outras mônadas. 
Ora, o universo em sua totalidade, em todos os seus níveis, acaba por se configurar como uma grande empresa coletiva. Isso supõe, diz Tarde (1893, p. 58), "que toda coisa é uma sociedade, que todo fenômeno é um fato social". O "psicomorfismo" - universalidade do espírito - implica desse modo um "sociomorfismo". As mônadas tendem a se associar, elas na verdade apenas agem possuindo outras, imprimindo-lhes seu desígnio próprio, seu projeto de universo particular. Todo ser quer apropriar-se dos seres que lhes são exteriores. Uma vez espiritualizado o universo, o "psicomorfismo" é elevado à condição de "sociomorfismo" ao fazer fundo sobre a espontaneidade e o querer das mônadas (ALLIEZ 1999, p. 22). Não apenas há almas por toda a natureza, mas também sociedades. Essas associações são a forma geral da atividade das agências espirituais. Ação ou exercício das tendências monádicas, imposição de sua substância própria, de um lado, acordo, associação, possessão e sociedade, de outro, são termos, ou melhor, gêneros de atividade intimamente ligados na filosofia da natureza ou neomonadologia de Tarde.

As mônadas, de um lado, são totalidades especiais, virtualidade ou meio universal que encarna uma ideia cósmica, de outro, apropriando-se dos seres que lhe são exteriores - e que lhe continuarão parcialmente exteriores mesmo uma vez apropriados -, elas mostram que nada podem sozinhas. A sociedade, "possessão recíproca, sob formas extremamente variadas, de todos por cada um" (TARDE 1893, p. 95), não é a inclusão de um elemento em um conjunto que lhe ultrapassa. $O$ todo não transcende a entrepossessão das mônadas. Cada uma empresta uma fração infima de sua própria complexidade a uma simplificação provisória e parcial que apenas retém dela uma parcela de seu 
ser. Uma totalidade desse modo obtida é mais simples que as partes no interior das quais ela circula ao modo de um agregado de formatações provisórias. $O$ todo não é uma totalidade, mas um esboço, traço que percorre as totalidades e que chega a fazê-las consentir em confiar uma parte de si mesmas (LATOUR 2011, p. 28). Ou seja, a potência coletiva, o acordo formalizado, não deixa de ser uma entidade artificial.

(...) seus elementos componentes, soldados desses diversos regimentos, encarnação temporária de suas leis, apenas lhes pertence por um lado de seu ser, e por outros lados escapam ao mundo que eles constituem. Esse mundo não existiria sem eles; mas, sem aquele, estes ainda seriam alguma coisa. Os atributos que cada elemento deve a sua incorporação no regimento não formam sua natureza completa; ele tem outras inclinações, outros instintos que procedem de arregimentações diferentes; outros enfim (...) que vêm de seu âmago, de si mesmo, da substância própria e fundamental na qual pode se apoiar para lutar contra a potência coletiva, mais vasta, porém menos profunda, da qual faz parte, e que não é senão um ser artificial, composto de lados e fachadas de seres (TARDE 1893, p. 80).

Como afirma Latour (2011, p. 26), não é possível dizer que as partes entram no interior de uma totalidade, mas sim que as totalidades simplificam uma porção de seus mundos para deixar circular entre elas um fragmento tomado provisoriamente como todo. Nesses termos, o todo é uma parte tomada por todo, nem maior nem transcendente, que circula entre as totalidades especiais que são as mônadas. A harmonia resultante não é outra coisa senão o efeito pelo qual as totalidades especiais ou mônadas se deixam percorrer, ao menos por uma parte de seu ser e por um breve período de tempo, por um grupo de características que as torna um pouco semelhantes entre si antes que comecem novamente a divergir. Estamos diante de uma ma- 
neira de explicação dos acordos monádicos que nos afasta, definitivamente, da composição ideal da natureza leibziniana .

Sabemos que são associações fortuitas e diretas entre as mônadas que explicam as regularidades da natureza. Sabemos também que, uma vez que a possessão é um fato universal e que o que é possuído são outros espíritos ou mônadas, podemos afirmar sem medo que há sociedades em toda a natureza, que a sociedade é um fato generalizado. Como já observamos quando da definição tardiana das propriedades psicológicas do espírito, o humano não é nada além de um caso particular de um fenômeno universal. Mas ele é um caso privilegiado. Ele oferece o modelo da causalidade que pode iluminar aquilo que, nas interações monádicas, nas associações dos mundos material e vital, escapa ao olhar direto do observador. Tarde buscará na observação dos fatos sociais a explicação dos meios precisos pelos quais essas associações se operam na totalidade do cosmos - em outros termos, por que meios os espíritos são sugestionáveis, como de sua irredutível heterogeneidade blocos provisórios podem se formar e ganhar o nome de acordos ou regularidades. A sociedade nos brinda, do ponto de vista tardiano, com uma causalidade sui generis, capaz de nos informar como as mônadas operam as "conversões" que garantem a imposição de uma forma estática ao dinamismo de fundo da natureza.

\section{DA SOCIEDADE DOS HOMENS À NATUREZA.}

Tarde estabelece em Les lois de l'imitation (1890) um objetivo claro: a edificação de uma "sociologia pura", voltada ao lado puramente "social" dos fatos humanos, abstração feita, 
no homem, de tudo o que é material ou vital (TARDE 1890, p. 57-58). Porém, no interior dessa depuração, espécie de obsessão da sociologia francesa do XIX, ávida em constituir para si um objeto e um campo preciso de aplicação, uma dimensão cosmológica do problema da sociedade se insinua nesse exclusivismo metodológico ${ }^{7}$. Uma neomonadologia que toma a sociedade e a tendência associativa inscrita nas ações monádicas como fatos universais, que explicam a criação e desenvolvimento de toda e qualquer realidade. Estabelecer, assim, uma sociologia "pura”, limitase à descrição do modo pelo qual o fato social em sua expressão antropológica figura como caso particular de uma processualidade geral.

Diante disso, Tarde chama a atenção para o privilégio que a vida humana em sociedade apresenta: ela nos revela suas "causas verdadeiras", os atos individuais de que é feita, o que em qualquer outro domínio da natureza é subtraído a uma "visão direta". Isso dispensa o sociólogo de recorrer a causas gerais que físicos e naturalistas são obrigados a criar sob os nomes de força, de energia ou de condições de existência, por exemplo, "paliativos verbais de sua ignorância do fundo claro das coisas”, dirá Tarde (1890, p. 61). Mas Tarde vai além. Não apenas o sociólogo pode dispensar esse recurso como ele pode fornecer os meios adequados para que físicos e naturalistas, por sua vez, façam o mesmo. As aquisições de uma sociologia que se define como "pura" são tomadas como fonte de transparência ao observador da natureza. Natureza esta que já se fizera translúcida a partir de

\footnotetext{
${ }^{7}$ Exclusivismo comumente acompanhado de uma ruptura ontológica entre homem e natureza. A sociologia de Émile Durkheim, contemporâneo e, sob muitos aspectos, adversário de Tarde, testemunha dessa atitude.
} 
sua pulverização em agências infinitesimais seguida de sua espiritualização.

Se o fundo das coisas é inacessível, afirma Tarde, a necessidade de fazer hipóteses para nelas penetrar se impõe: "Hypotheses fingo" (TARDE 1893, p. 65). O estabelecimento de um "ponto de vista sociológico universal", interpretação sociológica de todas as coisas, não é nada além dessa necessidade levada ao seu limite. Vimos o modo como Tarde se apoiou sobre a ciência na constituição de sua monadologia. Eis que a operação agora é distinta. É a interpretação sociológica de todas as coisas que deve provocar uma renovação em todos os domínios da ciência, destinados a tornarem-se ramos da sociologia .

Uma vez encontrado seu campo próprio de similitudes e repetições, uma ciência deve compará-las e observar o laço de solidariedade que as une às variações que lhes são concomitantes. O progresso de uma ciência consiste em substituir similitudes e repetições exteriores ao seu campo de aplicação por similitudes e repetições que lhe sejam interiores, por comparações de seu objeto com ele próprio tomado em seus múltiplos exemplares. No que diz respeito às sociedades, o caráter próprio de um fato social, qualquer que ele seja, é ser imitativo (TARDE 1898, p. 47). "Tudo o que é social, e não vital ou físico, nos fenômenos das sociedades, tanto em suas similitudes quanto em suas diferenças, tem a imitação como causa" (TARDE 1890, p. 110) .

Se o que permite às ciências adquirir cientificidade é o reconhecimento de seu domínio próprio de repetições, de regularidades observáveis, qualquer que seja o andar da realidade em que elas se dão, similitudes e repetições são os temas necessários das variações, e nisso nada singulariza o objeto da ciência social. "Toda repetição, social, orgânica 
ou física, não importa, ou seja, imitativa, hereditária ou vibratória (para nos atermos unicamente às formas as mais impressionantes e típicas da Repetição universal) procede de uma inovação" (TARDE 1890, p. 67). Uma invenção humana, que inaugura um novo gênero de imitação, é para a ciência social o que a formação de uma nova espécie é para a biologia, o que a aparição de um novo modo de movimento é para a física e o que a formação de um novo corpo é para a química. "Vemos desse ponto de vista o objeto da ciência social apresentar uma analogia assinalável com os outros domínios da ciência em geral e se reincorporar desse modo, por assim dizer, ao resto do universo no seio do qual ela fazia o efeito de um corpo estranho" (TARDE 1890, p. 64).

Para a sociologia se tornar científica ela teve de circunscrever seu objeto, não confundi-lo com similitudes e repetições que se dão em outros domínios da natureza. Mas, uma vez encontrado esse objeto, nada impede que os demais ramos da ciência possam buscar na sociologia um modelo de causalidade para o discernimento do que se passa alhures. Pois a sociologia apresenta o privilégio de uma visão "do interior", do conhecimento de "causas verdadeiras". Em vez de tentar dar a sociologia um aspecto científico fornecendo-lhe um modelo biológico ou mecânico, Tarde (1890, p. 61) propõe partir dos modelos encontrados na análise da sociedade e sua causalidade própria para a explicação do que se passa no restante do universo. Os processos de imitação ultrapassam, desse ponto de vista, os quadros estritamente sociológicos. A imitação é alçada ao estatuto de princípio metafísico. A causalidade exemplar ou imitação é a ação a distância de um espírito sobre outro. Estimulando e exercitando mutuamente suas tendências, um ser 
pode agir sobre o outro suscitando nele uma reação que tende a tornar-lhe semelhante ao primeiro. Esse processo, segundo Tarde, é facilmente verificável no domínio humano. Ora, como o comportamento humano é apenas um caso particular do comportamento universal, é possível generalizar e admitir que a causalidade exemplar dirija todos os elementos do universo (MILET 1970, p. 194).

“- Eu entendo por imitação toda marca de fotografia inter-espiritual, por assim dizer, quer ela seja desejada ou não, passiva ou ativa” (TARDE 1890, p. 46). A similitude das ações humanas resultante dessa interação entre espíritos é o fato social elementar, a verdade que a sociologia deve alcançar para eclodir. "Percebe-se facilmente, com efeito, que o fato intermental elementar, a sugestão exercida por um espírito sobre outro espírito no estado normal, é a unidade que se repete indefinidamente na vida social" (TARDE 1904, p. 79). Um grupo social é uma coleção de seres que se imitam, ou então que, mesmo sem se imitarem atualmente, se assemelham por traços que são cópias de um modelo antigo (TARDE 1890, p. 128). A imitação é a relação de um sujeito com um objeto que é ele próprio sujeito. Essa consciência de uma consciência não é uma impulsão física recebida ou fornecida, tampouco um transporte de força motora do sujeito ao objeto inanimado ou vice-versa, mas a transmissão de alguma coisa de interior, de mental, que passa de um dos sujeitos ao outro sem se perder ou diminuir-se nessa passagem (TARDE 1898, p. 56) .

As ações de um espírito sobre outro espírito são ações a distância; por elas se realiza uma causalidade de natureza superior, que consiste não na incompreensível produção de um efeito heterogêneo, completamente diferente de sua causa, como quando vibrações de éter produzem em nós uma sensação de cor, mas na reprodução da causa que se imprime e se assinala em seu efeito (TARDE 1901b, p. 05) . 
É como se Tarde não fizesse nada além de conceder à noção de "influência" seu sentido próprio, de causa que age a distância, sem sair de si mesma, para produzir seu efeito, redes imateriais de influência recíproca que se desenvolvem na superfície dos seres alterando-os sem os tocar (KARSENTI 1993, p. 24-25). Aquilo que circula através dessas redes ou "ondas de alma" (TARDE 1901, p. 05) são os únicos elementos que podem ser transmitidos contagiosamente de uma alma à outra: crenças e desejos. A imitação é um fenômeno de contágio da crença e do desejo, de transmissão dessas duas forças intimas. O que é imitado, "é sempre uma ideia ou um querer, um julgamento ou um desígnio, no qual se exprime determinada dose de crença e de desejo" (TARDE 1890, p. 204) .

$\mathrm{Na}$ dimensão antropológica da vida cósmica, na qual Tarde estabelece os limites de sua "sociologia pura", tudo se passa aos moldes de uma espécie de magnetização, relação entre modelo e cópia que mobiliza uma força potencial de crença e de desejo a partir de uma simpatia que é a fonte primeira da sociabilidade. A vida social se constitui como uma cascata de imitações sucessivas e encadeadas, uma sugestão de pessoa a pessoa. "O estado social, assim como o estado hipnótico, é apenas uma forma de sonho, um sonho de comando e ação. Ter apenas ideias sugeridas e acreditálas espontâneas: tal é a ilusão própria ao sonâmbulo e ao homem social" (TARDE 1890, p. 137). Tratar do problema especificamente humano na sociologia tardiana, do modo como os fluxos imitativos agem na conformação das sociedades, abstração feita do que é vital e físico, significa compreender como desejos e crenças exercem seu poder através da imitação (LAZZARATO 1999, p. 141).

Com sua "monadologia" e a operação fundamental que 
a sustenta, a abertura das mônadas leibzinianas e o reconhecimento de uma influência possível de uma sobre outra, Tarde estabeleceu a associação-possessão como fato universal, do qual a sociedade dos homens é um caso particular. $\mathrm{O}$ que os dados da "sociologia pura" lhe permitem pela clareza que apresentam - pois o observador pode observá-los "do interior" - é o reconhecimento da natureza da ação interespiritual que sustenta esse fato social primitivo em todas as escalas. Se as repetições hereditárias e vibratórias não são propriamente "imitações", seu efeito é análogo. Trata-se da imposição de um ritmo de repetição a partir de um elemento-chefe que o propaga "contagiosamente". Possuir, apropriar-se de outros agentes, configura-se como uma conversão espiritual cujo modelo é o da imitação do homem pelo homem .

Uma vez mais Bergson é preciso em suas observações a respeito de Tarde. Este retirara grande partido do raciocínio por analogia, procedimento essencial de seu método, afirma Bergson (1909a, p. 378). Se a essência do homem é ser imitador, a imitação desempenha nas sociedades dos homens papel análogo ao da hereditariedade nos organismos vivos e da ondulação nos corpos brutos. Se todas as similitudes se devem a repetições, as similitudes do mundo físico, químico e astronômico têm por causa movimentos periódicos (notadamente vibratórios), as similitudes do mundo vivo a transmissão hereditária ou geração, do mesmo modo que todas as similitudes de origem social são fruto da imitação (TARDE 1890, p. 74-75). Mas essa extensão analógica que Tarde opera a partir da sociedade dos homens vai mais longe que a afirmação de que inovações repetidas originam similitudes em cada andar da realidade. Ela permite afirmar "como" isso é possível. O que é estendido à "interioridade" 
das repetições físicas e vivas, inacessíveis à observação direta, é a clareza dos fatos sociais; o que é assim estendido é a causa de sua produção, o contágio do exemplo .

A operação metodológica que preza pela clareza que os fatos sociais apresentam ao observador figura como elemento complementar à percepção da insuficiência do leibzianismo na explicação dos acordos observáveis na natureza. Mais precisamente, ela informa a lógica própria que preside esses acordos: ação inter-espiritual ou relação de simpatia entre forças espirituais. Como afirma Karsenti (1993, p. 25), tomando a imitação como a forma antropológica da repetição universal, é possível entrever uma filosofia da natureza que subentende a filosofia social. Qualquer que seja o olhar adotado, do leitor de Leibniz e instaurador de uma nova monadologia ou do sociólogo buscando constituir as bases de sua ciência - supondo que pudéssemos realizar essa separação fora dos limites estreitos dessa exposição -, veríamos um universo que, em todos os seus níveis, se funda sobre a dinâmica associativa de forças mentais essencialmente comunicáveis .

Podemos então concluir a respeito da relação entre neomonadologia "e" sociologia que buscávamos elucidar da seguinte maneira. Constatada a insuficiência da monadologia de Leibniz na explicação dos acordos presentes em uma natureza pulverizada em uma miríade de agências independentes, cujo resultado é a abertura das mônadas e a processualidade associativa que elas passam a implicar, é uma ciência particular, a ciência social, que tem no fato imitativo seu objeto de análise, quem fornecerá os quadros precisos, a causalidade que possibilita compreender "do interior" aquilo que não se oferece "diretamente" ao olhar do filósofo ou do homem de ciência no campo da natureza . 
É verdade que essa extensão é tributária de certo espiritualismo que identificara anteriormente, no plano da análise monadológica, na matéria e na vida, uma atividade que é a marca do espírito. Mas sem a verificação, da ordem da precisão científica, sem a clareza pela qual essa atividade se desenvolve nas associações humanas, uma lacuna permaneceria na descrição do plano da natureza, condenados que estaríamos ao "como se" das operações analógicas. Contra essa ameaça de inacessibilidade ao fundo das coisas, a observação da vida do espírito em sociedade, influenciando e se deixando influenciar, participando das harmonias e da face regular da vida universal ao se assemelhar aos seus pares, vem oferecer sua transparência.

O espírito, encontrando assim sua própria imagem viva no enigmático universo, toma melhor consciência de sua própria realidade por esse reflexo que the aparece como uma realidade paralelamente indiscutível, subtraída aos golpes do ceticismo idealista. Ele tocou aí um inconcussum quid em que ele se apoia e que se apoia sobre ele, que se lhe assemelha já com ele e que se esforça consciente ou inconscientemente em se assimilar mais, seja pela simpatia seja pela antipatia que nasce entre eles (TARDE 1901, p. 04).

Semelhante postura coloca Tarde em uma singular posição no contexto do cientificismo sociológico do século XIX: por exemplo, com relação aquele de Durkheim. Se, com efeito, Tarde isola o fato social e reconhece sua especificidade, ao contrário de seu adversário, que afirmará a irredutibilidade não apenas metodológica, mas igualmente ontológica da sociedade ao restante da natureza, ele faz de seus privilégios, dos ganhos da ciência que se esforça em fundamentar, fonte de restituição de certeza às hipóteses de suas visões metafisicas: o que se passa entre nós "ilumina" o que se passa alhures. Tarde parece circular entre exigências e campos de investigação cuja relação não salta aos olhos de 
imediato. De um lado, fundamenta sua filosofia da natureza em um sistema monadológico um tanto em desuso e que ele acaba por reformular. De outro, compactua do espírito de busca de uma normatividade própria à ciência do social então nascente - o que lhe aproxima de seu adversário Durkheim pelo reconhecimento dessa necessidade, mas não pelos resultados aos quais chega e, menos ainda, pelas extensões que realiza e hiatos que suprime entre homem e natureza .

Abstract: This article presents the Gabriel Tarde's monadology and imitation philosophy to show its complementarity in the constitution of a "universal sociological point of view", the sociological interpretation of all phenomena, material (vibratory), biological (hereditary) and human (imitative). On the one hand Tarde establishes a neo-monadology by opening Leibniz's closed monads. The open monads constitutes, through their mutual possessions, the agreements and harmonies that Leibniz explained by the system of pre-established harmony. These agreements are monadic societies of many types who explain the constitution of any phenomenon. On the other hand Tarde tries, through its imitation philosophy, to provide a scientific substrate to an emerging sociology, taking the imitation as the anthropological aspect of an associative activity that is present in the entire cosmos. Thus, trying to purify to depurate the social science's own subject, Tarde find a kind of causality that, for the clarity by which she offers itself to the observer on the human societies, is extended to the entire nature, illuminating the obscure and inaccessible background in which the monadic associations take place .

Keywords: monad; agreement; science; society.

\section{REFERÊNCIAS}

ALLIEZ, Eric. Présentation: Tarde et le problème de la constitution. In: TARDE, Gabriel. Monadologie et sociologie. Paris: Institut Synthélabo,1999. p. 09-32.

BERGSON, Henri. Préface aux «Pages choisis» de Gabriel Tarde. In: _. Écrits philosophiques. Paris: PUF,1909a (2011).p. $377-379$. 
- Discours sur Gabriel Tarde. In: philosophiques. Paris: PUF, 1909b (2011). p. $\overline{375-377 .}$

. Les deux sources de la morale et de la religion. Paris: PUF, 1932 (2008).

DELEUZE, Gilles. A dobra: Leibniz e o Barroco. São Paulo: Papirus, 1988 (2011).

FICHANT, Michel. Science et métaphysique dans Descartes et Leibniz. Paris: PUF, 1998.

KARSENTI, Bruno. Introduction. In: TARDE, Gabriel. Les lois de l'imitation. Paris: Kimé, 1993. p. VII-XXVI .

LATOUR, Bruno. Gabriel Tarde. La société comme possession. La «preuve par l'orchestra». In: DEBAISE, Didier (éd.). Philosophie des possessions. Paris: Les presses du réel, 2011. p. 09-34.

LAZZARATO, Maurizio. Postface : Gabriel Tarde, un vitalisme politique. In: TARDE, Gabriel. Monadologie et sociologie. Paris: Institut Synthélabo, 1999. p. 103-150 .

- Puissances de l'invention: la psychologie économique de Gabriel Tarde contre l'économie politique. Paris: Institut Synthélabo, 2002.

LEIBNIZ, Gottfried W. Discours de métaphysique. In: - Discours de métaphysique suivi de Monadologie. Paris: Gallimard, 1686 (1995). p. 17-85.

- Système nouveau de la communications des substances et autres textes 1690-1703. Paris: Flammarion, 1695 (1994) . 
. De la nature en elle-même ou de la force immanente et des actions des créatures. In: . Oeuvres de G. W. Leibniz. Tome I. Paris: Aubier Montaigne, 1698 (1972). p. 345-351.

. Essais de Théodicée. Sur la bonté de Dieu, la liberté de l'homme et l'origine du mal. Paris: Flammarion, 1710 (1969) .

- Monadologie. In: - Discours de métaphysique suivi de Monadologie. Paris: Gallimard, 1714a (1995). p. 95-114.

. Princípios da natureza e da graça fundados na razão. In: __ . Discurso de metafísica e outros textos. São Paulo: Martins Fontes, 1714b (2004). p. 151-163.

MILET, Jean. Gabriel Tarde et la philosophie de l'histoire. Paris: Vrin, 1970.

- Bergson et le calcul infinitésimal ou la raison et le temps. Paris: PUF, 1974.

- Ontologie de la différence: une explorarion du champ épistémologique. Paris: Beauchesne, 2006.

MONTEBELLO, Pierre . L'autre métaphysique: essai sur Ravaisson, Tarde, Nietzsche et Bergson. Paris: Desclée de Brouwer, 2003.

TARDE, Gabriel. Les possibles, fragment d'un ouvrage de jeunesse inédit. In: Archives d'anthropologie criminelle. Tome XXV, p. 08-41, 1874 (1910) .

. Maine de Biran et l'évolutionnisme en psychologie. Paris: Institut Synthélabo, 1876 (2000). 
. La croyance et le désir. In: . Essais et mélanges sociologiques. Lyon et Paris: A. Storck et G. Masson, 1880 (1895). p. 235-308

- Les lois de la imitation. Paris: Les Empêcheurs de Penser en Rond, 1890 (2001) .

. Monadologie et sociologie. Paris: Les Empêcheurs de Penser en Rond, 1893 (1999) .

. La logique sociale. Paris: Les Empêcheurs de Penser en Rond, 1895a (1999).

. La variation universelle. In: . Essais et mélanges sociologiques. Lyon et Paris: A. Storck et G. Masson, 1895b. p. 392-429.

. Les lois sociales. Paris: Les Empêcheurs de Penser en Rond, 1898 (1999).

. L'action des faits futurs. In: Revue de métaphysique et de morale. no II, p. 119-137, 1901a .

- La psychologie inter-mentale. In: Revue internationale de sociologie. Tome IX. p. 01-15. 1901b .

- La psychologie et la sociologie. In: Annalles de l'institut internationale de sociologie. no 10. p. 67-81. 1904. 